

\title{
Uso de cupins (Isoptera: Insecta) como ferramenta no ensino de Ciências e Educação Ambiental
}

\author{
Lírio Cosme Junior', Luís Paulo Sant'ana², Conceição Aparecida dos Santos ${ }^{3}$
}

\begin{abstract}
Resumo: A percepção e interpretação das pessoas sobre alguns animais são oriundas de uma série de fatores históricos, culturais e sociais. No que se refere aos insetos, infelizmente, a maioria das pessoas associam tais organismos apenas a situações negativas. No entanto, sabemos da imensa importância desse grupo, no caso dos cupins, estes são organismos detritívoros da fauna de ecossistemas tropicais e desempenham um papel fundamental na ciclagem de nutrientes e na formação do solo. O objetivo deste trabalho foi aumentar o interesse de crianças do ensino fundamental pela ciência e educação ambiental, a partir do uso de cupins. O trabalho foi realizado com cerca de 400 alunos que entraram em contato direto com os insetos. Enquanto as crianças os visualizavam, foram discutidos temas que apontavam a importância dos cupins. No final das apresentações, solicitamos aos alunos que relatassem sobre os pontos que foram abordados e, por meio destes relatos, foi possível observar uma inversão das opiniões prévias, uma vez que eles citaram aspectos positivos relacionados aos cupins. Por fim, tivemos a oportunidade de conhecer a realidade das escolas visitadas e, ainda, de constatar como podemos diversificar nossas metodologias em sala de aula.
\end{abstract}

Palavras-chave: Modelos didáticos. Ensino fundamental. Crianças. Adolescentes.

Área Temática: Educação e meio ambiente.

\section{Use of termites Isoptera (Insecta) as a tool in teaching science and environmental education}

\begin{abstract}
The perception and interpretation of people on some animals come from a series of historical, cultural and social factors. With regard to insects, unfortunately, most people associate them only with negative situations. However, we know the immense importance of this group and in the case of termites, these are detritivores organisms related to the fauna of tropical ecosystems and play a key role in nutrient cycling and soil formation. The objective of this study was to increase the interest of elementary school children in science and environmental education, from the use of termites. The study was conducted with 400 students who came into direct contact with the insects, While children visualized, they were discussed themes which showed the importance of termites. At the end of the presentations, we ask students to report on the points that were addressed, and through these reports we observed a reversal of previous opinions, since they cited positive aspects related to termites. Finally, we had the opportunity to know the reality of the schools visited, and also to see how we can diversify our methodologies in the classroom.
\end{abstract}

Keywords: Didactic models. Elementary school. Children. Teenagers.

Thematic area: Environment and Education.

\footnotetext{
${ }^{1}$ Discente do Curso de Entomologia, nível de Doutorado UFV.E-mail: liriomago@yahoo.com.br

${ }^{2}$ Discente do Programa de Pós-Graduação em Biologia Animal da UFVJM. E-mail: luiscarbonita@yahoo.com.br

${ }^{3}$ Doutora em Biologia Celular e Molecular pela Universidade Estadual Paulista Júlio de Mesquita Filho Docente da UFVJM e Coordenadora do Projeto. Departamento de Ciências Biológicas. Laboratório de Histologia. Rua da Glória, 187/Bairro centro/ CEP: 39100000 - Diamantina/ MG. Telefone: (38) 88113218. Email: conceicaoufvjm@gmail.com
} 


\title{
El uso de las termitas (Isoptera: insectores) como una herramienta en la enseñanza de la Ciencia y la Educación Ambiental
}

Resumen: La percepción y la interpretación de la gente en algunos animales provienen de una serie de factores históricos, culturales y sociales. Con respecto a los insectos, por desgracia, la mayoría de las personas les asocian únicamente con situaciones negativas. Sin embargo, sabemos que la inmensa importancia de este grupo y en el caso de las termitas, estos son detritívoros organismos relacionados con la fauna de los ecosistemas tropicales y juegan un papel clave en el ciclo de nutrientes y la formación del suelo. El objetivo de este estudio era aumentar el interés de los niños de primaria en la ciencia y la educación ambiental, a partir de la utilización de las termitas. El estudio se realizó con 400 estudiantes que estuvieron en contacto directo con los insectos, Mientras que los niños visualizados, se discutieron temas que mostraron la importancia de las termitas. Al final de las presentaciones, pedimos a los estudiantes que informe sobre los puntos que se abordaron, ya través de estos informes se observó una reversión de las opiniones anteriores, ya que citaron aspectos positivos relacionados con las termitas. Por último, hemos tenido la oportunidad de conocer la realidad de las escuelas visitadas, y también para ver cómo podemos diversificar nuestras metodologías en el aula.

Palabras clave: Modelos didácticos. Escuela primaria. Niños. Adolescentes.

Área temática: Medio Ambiente y Educación.

\section{Introdução}

Os insetos em geral constituem o grupo animal com maior número de espécies da face da Terra (GULLAN; CRANSTON, 2014) e acredita-se que o número absoluto seja superior a cinco milhões de espécies (BARBIERI, 2010). Eles desempenham importante papel ecológico, pois atuam como herbívoros, decompositores, predadores e parasitóides. Além disso, ocupam lugar de destaque na vida socioeconômica da maioria das sociedades humanas (COSTA-NETO, 1998; PEMBERTON, 1999). A influência cultural dos insetos pode ser sentida na literatura, língua, música, artes, história representativa, religião e recreação de diferentes sociedades, tanto passadas quanto contemporâneas (LENKO E PAPAVERO, 1996; COSTA-NETO, 2000a).

Se considerarmos a definição acadêmica, os insetos são animais do filo Arthropoda que apresentam corpo segmentado em cabeça, tórax e abdômen e três pares de pernas (CAJAIBA, 2013). Diferentemente do conceito acadêmico, o senso comum julga os insetos como organismos nojentos, perigosos, repugnantes e inúteis. Em diferentes contextos sócio-culturais, o termo "inseto" é empregado como uma categoria taxonômica ampla que reúne animais não sistematicamente relacionados, além dos próprios insetos da categoria lineana (COSTA-NETO, 2000b).

\begin{abstract}
A construção do domínio etnozoológico "Inseto" foi explicada por meioatravés da hipótese da ambivalência entomoprojetiva, segundo a qual os seres humanos tendem a projetar sentimentos de nocividade, periculosidade, repugnância, medo e menosprezo aos animais associados com o grupo "Inseto" determinado culturalmente (COSTA-NETO, 2000b).
\end{abstract}

Em geral, as atitudes dos indivíduos com relação aos animais podem ser influenciadas por muitos fatores, tais como: abundância do animal; sensação tátil; sensação visual; crença na espiritualidade; ideia de sujeira ou limpeza; associação do animal a doenças; crença na fragilidade ou resistência do animal; benefícios ou prejuízos que o animal possa trazer; desconforto que o animal possa gerar; aparência; e conhecimento ou desconhecimento sobre o animal (MORALES et al., 1997).

Hoyt e Schultz (2002) salientam que os seres humanos ao se tornarem progressivamente estranhos ao mundo natural, perderam a habilidade de distinguir um inseto do outro; como resultado, as atitudes negativas foram generalizadas para quase todos os insetos. Tal fato é aproveitado pelas indústrias produtoras de praguicidas, 
que lançam suas campanhas no sentido de combater esses organismos indiscriminadamente e cada vez em maior número (RAMOS-ELORDUY, 1994).

A "cultura do inseticida" é refletida em artigos de revistas e em várias outras formas de cultura popular. A própria indústria cinematográfica corrobora essa atitude, pois os filmes raramente projetam imagens positivas dos artrópodes. Ao contrário, eles exploram imagens sinistras de perigo ou morte, imagens chocantes que provocam medo e pavor e também imagens caricaturais (antropomorfizadas) para ridicularização (MERTINS, 1986).

Investigadores ligados à área da biologia da conservação chegaram à conclusão de que os fatores emocionais são essenciais em qualquer ação conservacionista bem-sucedida. Mudando-se a emoção, a maneira pela qual os objetos (nesse caso, os invertebrados) são percebidos é transformada (COSTA-NETO, 2004). Segundo Maturana (2001), “a transição de um domínio de ação para outro é sempre emocional". Sabe-se que, na maior parte das vezes, o medo quase psicótico de insetos e outros animais está aliado de uma total falta de informação sobre o animal em questão (SMITH, 1934).

De maneira geral, os indivíduos só conhecem esses animais por lhes causarem doenças e outros problemas. Assim, um processo de aprendizagem baseado em estímulos sensoriais adequados poderia levar a mudanças de atitudes dos indivíduos com relação aos insetos, tornando-os mais toleráveis ao convívio com esses organismos (COSTA-NETO; PACHECO 2004).

Os Cupins são insetos da ordem Isoptera, contendo cerca de 3000 espécies descritas no mundo (CONSTANTINO, 2015). Esses insetos apresentam um sistema social singular com diferentes formas morfológicas ou castas (KRISHNA; WEESNER, 1969). Os cupins apresentam uma organização social bem interessante, não oferecem risco à saúde e são coletados em grande número, portanto, foram utilizados como modelo nas apresentações para crianças do ensino fundamental.

Este trabalho de extensão foi baseado na ideia de propor um ensino de ciências que não apenas responda às questões dos alunos, mas que também introduza uma postura relativa ao universo científico (CHASSOT, 2000). Sendo assim, o principal objetivo deste projeto foi auxiliar na construção de uma nova visão dos alunos do Ensino Fundamental da cidade de Diamantina em relação aos insetos, utilizando os cupins como grupo modelo.

\section{Seleção das escolas e preparo do material}

Este trabalho foi realizado durante o período de 2009 a 2013, foram selecionadas escolas de Ensino Fundamental de Diamantina que tivessem interesse em receber o projeto. Para a realização das apresentações, os ninhos foram quebrados em pedaços com ajuda de uma picareta de jardinagem e, em seguida, armazenados em baldes comuns cobertos por sacos plásticos escuros para que não saíssem e fossem incomodados pela luz. É importante mencionar que em todas as atividades foram utilizados ninhos de cupins da subfamília Nasutitermitinae dos gêneros Cornitermes ou Nasutitermes (Fig 1). Os ninhos foram coletados com, pelo menos, um dia de antecedência pela coordenadora do projeto, utilizando-se uma licença permanente para coleta de material zoológico concedida pelo Instituto Brasileiro do Meio Ambiente e dos Recursos Naturais Renováveis (IBAMA). Durante todo o tempo em que os fragmentos estavam no laboratório, esses eram borrifados com água para evitar a morte dos indivíduos.

Os pedaços de ninhos foram distribuídos em bandejas brancas para grupos de até quatro alunos, sendo que o número de bandejas e grupos variou conforme o tamanho das turmas. Essas bandejas com os insetos foram cuidadosamente verificadas antes da apresentação para que não ocorresse a presença de aranhas ou escorpiões que, às vezes, podem ser encontrados nos ninhos. (Fig 2). 


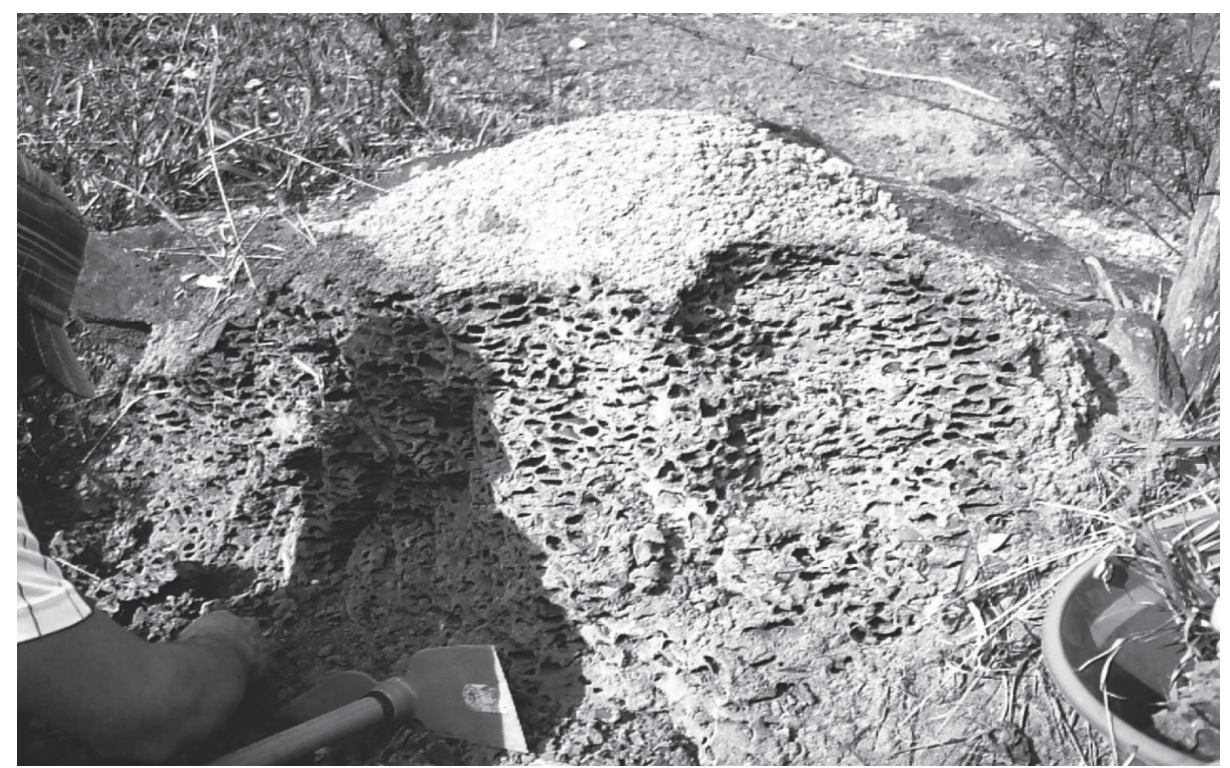

Figura 1 - Quebra dos pedaços de um ninho de Cornitermes sp.

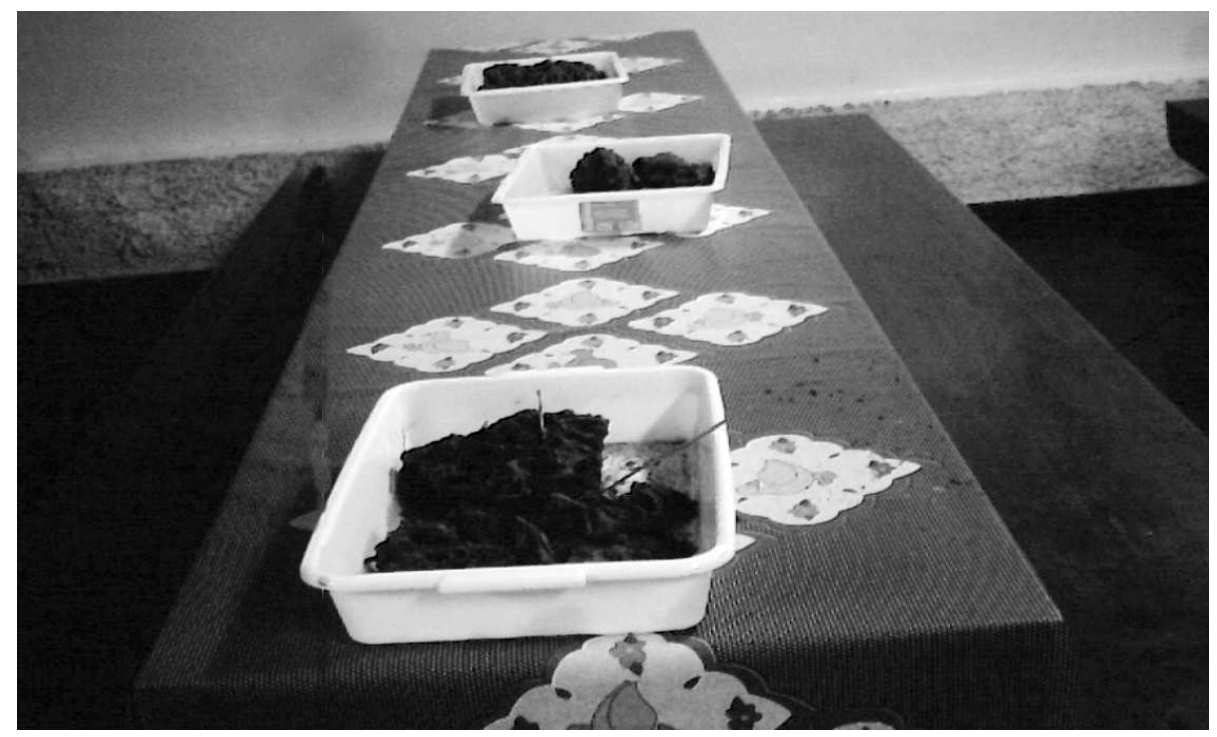

Figura 2 - Montagem da oficina para ser apresentada aos grupos de alunos de uma escola de Diamantina.

\section{Realização da oficina}

A oficina foi composta de uma apresentação inicial, em que tivermos a oportunidade de conhecer os alunos e suas opiniões a respeito dos cupins. Após essa introdução, os alunos foram colocados em contato direto com os insetos. No decorrer da exposição prática, representantes de cada casta (ninfa, operário, soldado e uma rainha conservada em álcool 80\%) foram distribuídos em pequenos tubos para uma explicação mais detalhada. Cada grupo de alunos recebeu tiras de papel e pinças para que as crianças pudessem manipular os cupins na bandeja.

Enquanto os estudantes interagiam com os cupins, foram discutidos temas sobre a importância desses insetos no meio ambiente, como recicladores, aeradores do solo e outros aspectos relevantes da biologia dos cupins como: divisão de castas, organização e comunicação. Ao mesmo tempo, os alunos expunham suas dúvidas e experiências com os cupins. Posteriormente, foi solicitado aos alunos que relatassem por meio de desenhos ou textos o que haviam aprendido em relação aos cupins. (Fig 3) 




Figura 3 - Alunos interagindo com o material e refletindo sobre a atividade por meio de textos e desenhos.

\section{Discutindo os resultados}

No início da atividade observamos que a maioria dos alunos relacionava os cupins a pragas urbanas que degradam mobílias, paredes e telhados. Tais ideias foram suportadas por relatos pessoais de alguns estudantes que chegaram a perguntar como era o combate dos cupins ao compartilharem casos de infestação em suas casas ou lugares que frequentavam. Essa atribuição de um caráter de praga aos insetos pelas pessoas é também encontrada em alguns outros trabalhos como o de COSTA-NETO \& PACHECO, 2004 e ULYSSÉA et al. 2010.

No que diz respeito aos impactos da oficina, durante a interação com os cupins os alunos mostraram considerável interesse pela atividade e muitos, que inicialmente estavam com repulsa desses insetos, ao final da oficina, já os colocavam na mão. Além disso, podemos observar por meio dos relatos finais uma inversão das opiniões relacionadas aos organismos estudados, uma vez que citaram a importância dos cupins para os ecossistemas bem como assinalaram representativamente à divisão de castas, que é algo marcante nas colônias de Isoptera. O trabalho de Cajaiba e Silva (2015) também pauta mudanças de pontos de vistas negativos ligados aos insetos ao utilizar estes organismos como ferramentas no ensino de Ciências e Educação ambiental. Portanto, acreditamos ter dado o primeiro passo para a redução do medo desses insetos por parte dos alunos participantes do projeto. Em outras palavras, a realização deste trabalho contribuiu para desmistificar a ideia de que os insetos são apenas seres associados a prejuízos e que nos atacam. E, por isso, espera-se que a receptividade apresentada pelos alunos a esses organismos contribuirá para que, no futuro, a preservação não seja apenas de espécies "carismáticos"; mas também das espécies de animais invertebrados, que, igualmente às demais, apresentam papéis fundamentais na manutenção dos ecossistemas. Por fim, tivemos a oportunidade de conhecer a realidade das escolas visitadas, dos alunos e, ainda, de como podemos diversificar nossas metodologias em sala de aula por meio de um ensino mais contextualizado e prático, o que certamente é visto como fator enriquecedor, principalmente se considerarmos o fato de que a esquipe extensionista era proveniente de um curso de licenciatura.

\section{Agradecimentos}

Os autores agradecem aos alunos do Curso de Ciências Biológicas da UFVJM que atuaram como discentes extensionistas de forma voluntária, às Escolas públicas de Diamantina pela parceria e aos técnicos dos Laboratórios de citologia e histologia da UFVJM por contribuírem no desenvolvimento de todas as atividades. As atividades desenvolvidas receberam apoio financeiro da Pró-reitoria de Extensão (Proexc) da UFVJM. 


\section{Referências bibliográficas}

BARBIERI, E. Biodiversidade: A Variedade de Vida no Planeta Terra. São Paulo, 2010.

CAJAIBA, R.L. Utilização de uma Metodologia Estocástico-Dinâmica para simular a resposta de Coleoptera cavernícolas a gradientes ambientais e de perturbação antropogênica. 2013.128p. Dissertação (Mestrado em Engenharia do Ambiente) Utad, Portugal, 2013.

CAJAIBA, R.L.; SILVA, W.B. Percepção dos alunos do ensino fundamental sobre os insetos antes e após aulas práticas: um estudo de caso no município de Uruará-Pará, Brasil. Bananeiras-PB: Revista Lugares de Educação, v. 5, n. 11, p. 118-132 2015.

CHASSOT, Attico Inácio. Alfabetização científica: novas alternativas para novas exigências. Educação em Foco. Juiz de Fora: Editora UFJF, mar/set.v.5, n.1, p. 29-42, 2000.

CONSTANTINO, R. Cupins do Cerrado. 1 ed. Rio de Janeiro: Technical Books Editora. 2015. 167p.

COSTA NETO, E. M. O significado do Ortóptera (Arthropoda, Insecta) no Estado de Alagoas. Sitientibus, v.18, p. 9-17, 1998.

COSTA NETO, E. M. The significance of the category 'insect' for folk biological classification systems. Journal of Ecological Anthropology, v.4, p 70-75. 2000a.

COSTA NETO, E. M. Introdução à etnoentomologia: considerações metodológicas e estudo de casos. Feira de Santana: Universidade Estadual de Feira de Santana, 2000b. 131p.

COSTA-NETO EM, PACHECO JM: A construção do domínio etnozoológico "inseto" pelos moradores do povoado de Pedra Branca, Santa Terezinha, Estado da Bahia. Acta Scientiarum Biological Sciences, 26:81-90, 2004.

GULLAN, P. J.; CRANSTON, R. S. The insects: an outline of entomology. 5 ed. Oxford, UK: Blackwell Science, 2014. 624p.

HOYT, E.; SCHULTZ, T. Insect lives: stories of mystery and romance from a hidden world. Harvard University Press, 2002. 368p.

KRISHNA, K.; WEESNER, F.M. Biology of termites. New York: Academic Press. (Eds). v.1, 1969. 1241p.

LENKO, K. \& PAPAVERO, N. Insetos no folclore. 2. ed. São Paulo: Plêiade, 1996. 468p.

MATURANA, R. H. Cognição, ciência e vida cotidiana. Belo Horizonte: Ed. UFMG, 2001. 203p.

MERTINS, J. W. Arthropods on the screen. Bull. Ent. Soc. Am., Palo Alto, v.32, p. 85-90, 1986.

MORALES, A. G. et al. Estudo comparativo das atitudes de estudantes de Assis, SP, frente aos animais invertebrados. In: Resumos da IV Jornada de Educação, Assis: Unesp, p. 2, 1997.

PEMBERTON, R.W. Insects and other arthropods used as drugs in Korean traditional medicine. J. Ethnopharmacol., v.65, p.207-216, 1999.

RAMOS-ELORDUY, J. ¿Usted ya probó los insectos comestibles? UNAM Hoy, Cidade do México, v.3, n.12, p.61-66, 1994.

SMITH, R. C. Hallucinations of insect infestation causing annoyance to man. Bull. Brooklyn Ent. Soc., Brooklyn, v.29, p.208-210, 1934.

ULYSSÉA, M.A.; HANAZAKI, N. \& LOPES, B.C. Percepção e uso dos insetos pelos moradores da comunidade do Ribeirão da Ilha, Santa Catarina, Brasil. Biotemas, 23, 3, 191-202, 2010. 